\title{
Association of Mobile Phone Usage in Patients with Temporomandibular Joint Disorders - A Comparative Study
}

\author{
M. Sudhaa Mani, S. Yasmeen Ahamed, Nanitha Lakshmi Kavithagiri, P. Ambiga, \\ G. Sivaraman, N. Balan \\ Department of Oral Medicine and Radiology, Vivekanandha Dental College for Women, Tiruchengode, Tamil Nadu, India
}

Email for correspondence: drsudhaamanimds@gmail.com

\begin{abstract}
Context: Excessive usage of mobile phone is stated as an addictive behavior and is known to evolve into a complex chain of psychosomatic behavioral patterns. With prolonged usage, it has been scientifically proven to cause alterations in muscle behavior and neuromuscular proprioception in the head-and-neck region. Guidelines of the American Academy of Orofacial pain suggest a strong link between temporomandibular joint disorders (TMD) and cervical spine. Objective: The definite purpose of the present study was to evaluate the relationship between long-term mobile usage and craniocervical posture in patients with TMD. Materials and Methods: Participants in the study were screened for TMDs using research diagnostic criteria-TMD Axis I screening questionnaire (2013) and categorized into three groups. Thirty patients with TMD are taken in the study, of which 27 were females. Twenty individuals without TMD served as the controls. Mean age range of subjects is 23.4 years. Three linear and two angular measurements were evaluated in the lateral profile photographs. On the lateral cephalograms, two linear and angular measurements were carried out. Results: Highly significant was obtained in Group 2 concerning mobile phone use duration $(P<0.001)$ and frequency $(P<0.001)$. Conclusion: The interlink between the mobile phone usage and cervicogenic signs appeared to be more common in the TMD group.
\end{abstract}

Key words: Cervical curvature angle, craniocervical angle, forward head posture, lateral cephalogram, mobile phone usage, temporomandibular joint disorders

\section{INTRODUCTION}

Guidelines of the American Academy of Orofacial Pain suggests a strong link between temporomandibular joint disorders (TMD) and cervical spine. ${ }^{[1]}$

\section{Role of Mobile Phone Usage in Craniocervical Posture}

The hypothesis about painful symptoms of TMD is said to precede events of muscle hyperactivity

\begin{tabular}{|l|l|}
\hline Quick Response Code & Article Info: \\
\hline doi: 10.5866/2019.11.10079 & $\begin{array}{l}\text { Received: 08-07-2019 } \\
\text { Revised: 09-08-2019 } \\
\text { Accepted: 14-08-2019 } \\
\text { Available Online: 01-10-2019, (www. } \\
\text { nacd.in) ( ) NAD, 2019 - All rights reserved }\end{array}$ \\
\hline
\end{tabular}

due to various parafunctional and position related habits. The stomatognathic system is not a stranger to a wide range of daily activities that are influenced by stance in the upper half of the human anatomy. Excessive usage of mobile phone is stated as an addictive behavior and is known to evolve into a complex chain of psychosomatic behavioral patterns. ${ }^{[2]}$ With prolonged usage, it has been scientifically proven to cause alterations in muscle behavior and neuromuscular proprioception in the head-and-neck region. From a structural viewpoint, the musculoskeletal system consists of integrated complex sensory and motor framework that works in harmony with the nervous system. Inference of various literature expresses its concern toward how modern lifestyle factors such as usage of mobile phone and laptop causes debilitating changes in craniocervical posture. ${ }^{[3-5]}$ 
Average values for cervical lordosis is postulated as $21-34$ in the literature. ${ }^{[6,7]}$ Values above 40 and below 20 were found to be correlated with cervicogenic symptoms. ${ }^{[7]}$ Diagnostic interventions for craniocervical posture assessment in abused conditions will help guide the individuals through the better understanding of the prevention of TMDs. Hence, the present study was aimed to evaluate the association between craniocervical posture in longterm mobile phone users and TMDs.

\section{MATERIALS AND METHODS}

The study protocol was approved by the Institutional Ethical Committee, Reference noVDCW/IEC/111/2018; registration under No. ECR/784/Inv/TN2015 issued under rule 122 DD. An informed consent form was signed by individuals willing to participate in the study.

Sample source includes patients reporting to the Department of Oral Medicine and Radiology in Vivekanandha Dental College for Women, Namakkal district. It is an analytical study design. The sample size included 50 patients, of which 20 patients with no TMD served as the controls. Patients diagnosed with TMDs (30 patients) were categorized into Groups 1 and 2. Group 1 (15 cases) are individuals with average use of the mobile phone with frequency $>3$ and $5 \mathrm{~h} /$ day, duration 3 and 6 years and Group 2 ( 15 cases), and average use of the mobile phone with frequency $>5 \mathrm{~h} /$ day and duration - $>6$ years.

Clinical evaluation for TMDs was carried out based on Axis I screening questionnaire of the research diagnostic criteria-TMD criteria, 2013 by an oral medicine specialist. ${ }^{[8]}$

Inclusion criteria include individuals with age ranging between 18 and 40 years with established pain and joint disorders of TMD based on diagnostic decision tree.

Exclusion criteriawereasfollows:Patients(1)under medication for myalgia, headache, insomnia/sleep disorders, (2) following regular physical exercise, yoga regimes, (3) systemic musculoskeletal disorders such as cervical spondylitis and osteoarthritis, (4) degenerative TMD disorders and subluxation, and (5) morphologically debilitating conditions, psychiatric disorders, and other neurologic disturbances.

\section{Photogrammetry Specifications}

The individuals were photographed from their left lateral side using standardized protocols according to Lee et al., as shown in Figure 1, with their glance oriented toward the wall in front of them. ${ }^{[9]}$ Photographs were taken using digital camera Canon Eos 700D, 18 megapixels at a fixed distance approximately $1.5 \mathrm{~m}$ from the patient's left side, the camera was placed on a tripod. A free-hanging plumb line was used to define the right vertical axis on the photographs. Three linear measurements which include Ear- VP, C7$\mathrm{VP}$, and SH-VP and two angular measurements Eye-Ear-C7, and Ear-C7-Eye were made using i-Pinpoint measurement tool, and angle measure tool.

\section{Reference Lines Include}

- Eye - lateral corner of the eye

- Ear - most superior portion of the external auditory meatus

- $\mathrm{C} 7$ - spinous process of the $7^{\text {th }}$ cervical vertebrae

- HP - horizontal plane through $\mathrm{C} 7$ perpendicular to VP

- $\mathrm{SH}-$ acromial joint of the shoulder.

\section{Lateral Cephalogram Assessment}

Lateral cephalogram was taken using Newtom Panoramic Radiograph Machine with the following exposure parameters (time $-8.76 \mathrm{~s}, 0.004-0.03$ $\mathrm{msv} / \mathrm{square} \mathrm{cm}$ ), number needed to treat (NNT) software was used for cephalometric measurements that includes craniocervical angle (CCA), cervical curvature angle (CCA), suboccipital space ( $\mathrm{C} 0-\mathrm{C} 1$ distance), and atlas-axis distance (C1-C2 interval), respectively [Figure 2].

1. Craniocervical angle (CCA): The angle between McGregor plane (tangent drawn from most inferior surface of the occipital bone until it reaches the posterior nasal spine on the hard palate) and tangent line to the posterior surface of odontoid apophysis

2. Cervical curvature angle (C3-C6): The angle between the extended line from the posterior margin of the third and sixth cervical vertebral body

3. Suboccipital Space (C0-C1 distance): The perpendicular distance from the base of the occipital bone to the posterosuperior point of the first cervical vertebra

4. Atlas-axis distance (C1-C2 distance): The perpendicular distance from the most inferiorposterior point of the posterior arch of the atlas to the most superoposterior point of the spinous process of the axis. 


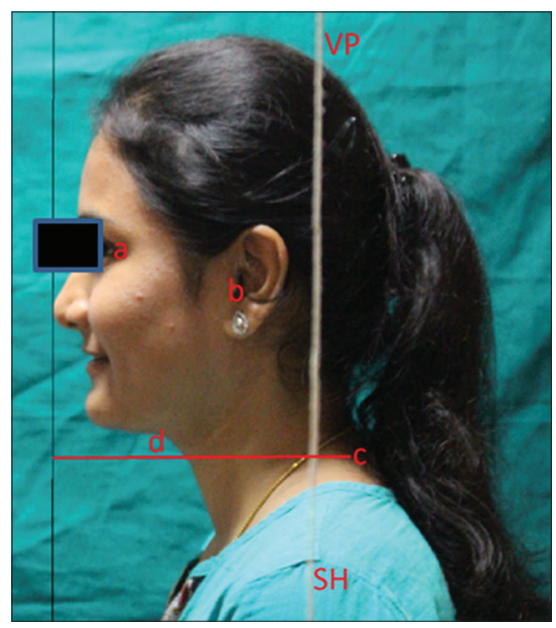

Figure 1: Landmarks on a lateral profile photograph

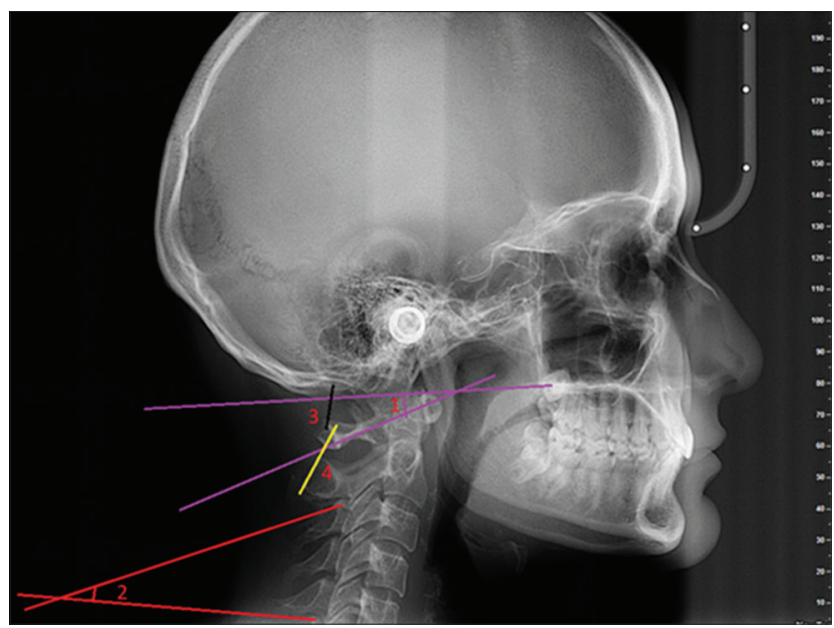

Figure 2: Landmarks on lateral cephalogram

(1) Craniocervical angle (CCA); (2) cervical curvature angle (C3-C6); (3) suboccipital space (C0-C1 distance); (4) atlas-axis distance (C1-C2 distance)

\section{Mobile Phone Use}

A questionnaire regarding mobile phone use includes the type of mobile phone use, the years of mobile phone use, the average daily mobile phone usage, and the activity mobile phone was predominantly used. The frequency and duration of mobile phone usage were assessed based on the percentage of the activity recorded on the battery app of the individual's phone, which is given in Graph 1.

\section{Statistical Analysis}

Statistical analysis was performed through the SPSS $^{\circledR}$ IBM $^{\circledR}$ statistics version 20.0 (IBM Corp., Armonk, NY, USA). The normality of the

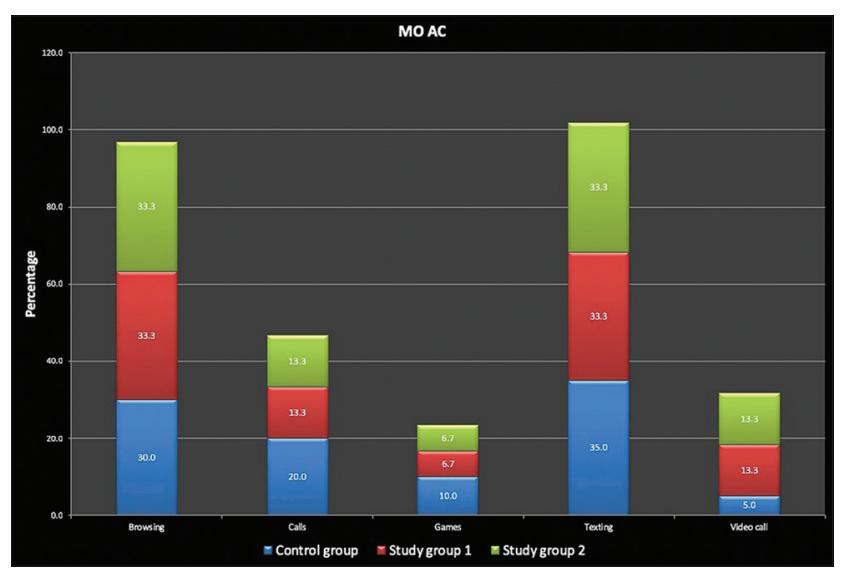

Graph 1: Activities of mobile phones predominantly used for

variables was checked. The student's t-test was used for between-group comparison of the normally distributed variables. Analysis of variance test was applied to assess the association between the measurements obtained from photographs, lateral cephalogram, and the values obtained from a questionnaire regarding mobile phone use. Results were considered as "statistically significant" when $P<0.001$.

\section{RESULTS}

Measurements from individuals with and without TMD were carried out using a single observer. Table 1 gives mean values of neck flexion angle (cervical curvature angle) that was 14.93 and 16.67 for Group 1 and Group 2, respectively. The mean values in Group 2 were higher when compared to controls, which were 15.70 . Table 2 gives a comparison of cephalometric measurements between the control group and Group 1 and Group 2, and the suboccipital space distance was profoundly decreased in study Group 2 with a value mean value of $1.81 \mathrm{~mm}$. An increase in the mean value of the atlantoaxial distance of $4.48 \mathrm{~mm}$ was observed in study Group 2 in comparison to controls, which was about $2.51 \mathrm{~mm}$.

Results of the photogrammetric measurements in Graph 2 reveal a reduced distance of $3.01 \mathrm{~cm}$ between the cervical spinous process and the vertical plumb line. Graph 3 shows changes in study Group 2 in comparison with the controls, where there is an increase in head flexion angle of $16.67^{\circ}$. These values suggest a reduction in horizontal length to the vertical plumb line and cervical spinous process and increased head flexion angle suggestive of forwarding head posture. 
Table 1: Comparison of photographic measurements between control group and Group 1 and Group 2

\begin{tabular}{|c|c|c|c|c|c|}
\hline Photographic measurements & Groups & $\mathbf{n}$ & Mean \pm SD & ANOVA & $\boldsymbol{P}$ \\
\hline \multirow[t]{4}{*}{ EAR_VP $(\mathrm{CM})$} & Control group & 20 & $2.04 \pm 0.38$ & 0.029 & 0.971 \\
\hline & Study Group 1 & 15 & $2.01 \pm 0.37$ & & \\
\hline & Study Group 2 & 15 & $2.02 \pm 0.26$ & & \\
\hline & Total & 50 & $2.02 \pm 0.34$ & & \\
\hline \multirow[t]{4}{*}{$\mathrm{C} 7-\mathrm{VP}(\mathrm{CM})$} & Control group & 20 & $3.22 \pm 0.58$ & 0.698 & 0.503 \\
\hline & Study Group 1 & 15 & $3.21 \pm 0.61$ & & \\
\hline & Study Group 2 & 15 & $3.01 \pm 0.48$ & & \\
\hline & Total & 50 & $3.15 \pm 0.56$ & & \\
\hline \multirow[t]{4}{*}{$\mathrm{SH}-\mathrm{VP}(\mathrm{CM})$} & Control group & 20 & $2.92 \pm 0.55$ & 0.288 & 0.751 \\
\hline & Study Group 1 & 15 & $2.96 \pm 0.64$ & & \\
\hline & Study Group 2 & 15 & $2.81 \pm 0.54$ & & \\
\hline & Total & 50 & $2.90 \pm 0.57$ & & \\
\hline \multirow[t]{4}{*}{ EY-EA-C7 (DEGREE) } & Control group & 20 & $139.20 \pm 4.99$ & 0.612 & 0.547 \\
\hline & Study Group 1 & 15 & $141.73 \pm 7.35$ & & \\
\hline & Study Group 2 & 15 & $141.13 \pm 9.15$ & & \\
\hline & Total & 50 & $140.54 \pm 7.09$ & & \\
\hline \multirow[t]{4}{*}{ EA-C7-EY (DEGREE) } & Control group & 20 & $15.70 \pm 3.15$ & 0.855 & 0.432 \\
\hline & Study Group 1 & 15 & $14.93 \pm 3.35$ & & \\
\hline & Study Group 2 & 15 & $16.67 \pm 4.45$ & & \\
\hline & Total & 50 & $15.76 \pm 3.63$ & & \\
\hline
\end{tabular}

Ear-VP (CM): Distance between external auditory meatus and vertical plumb line (VP); C7-VP (CM): Distance between cervical spinous process (C7) and vertical plumb line (VP); SH-VP (CM): Distance between acromial joint of shoulder and corresponding parallel line to the VP; EY-EA-C7 (Degree): Head flexion angle, angle formed between EY (landmark on outer canthus of eye); EA (most superior point on external auditory meatus); and C7 (Cervical spinous process); EA-C7-EY (Degree): Neck flexion angle, angle formed between EA (most superior point on external auditory meatus); C7 (Cervical spinous process); EY (landmark on outer canthus of eye). ANOVA: Analysis of variance

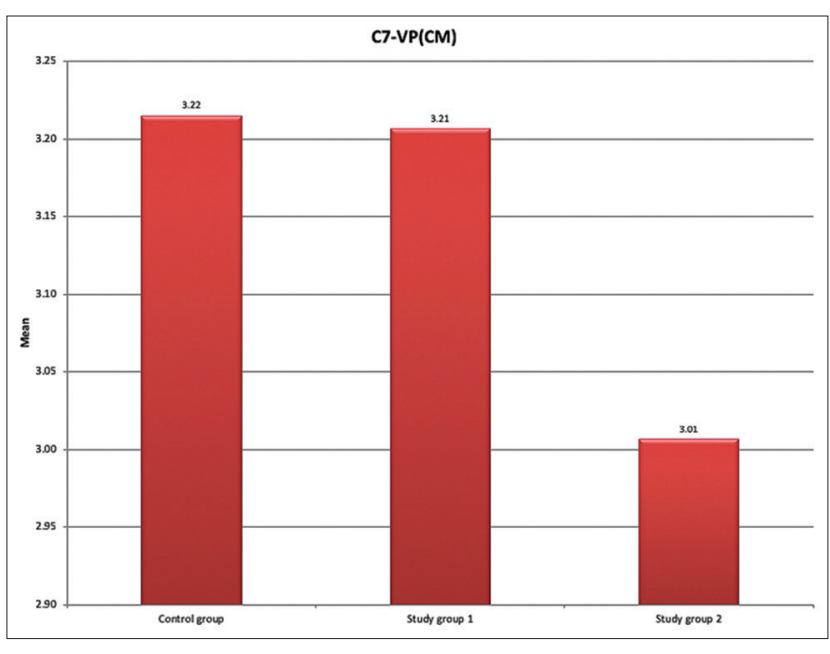

Graph 2: Study Group 2 shows reduced horizontal length to the vertical plumb line and cervical spinous process

C7-VP (CM) - Distance between cervical spinous process (C7) and VP (Vertical plumb line) Graph 3 shows the cephalometric assessment between the

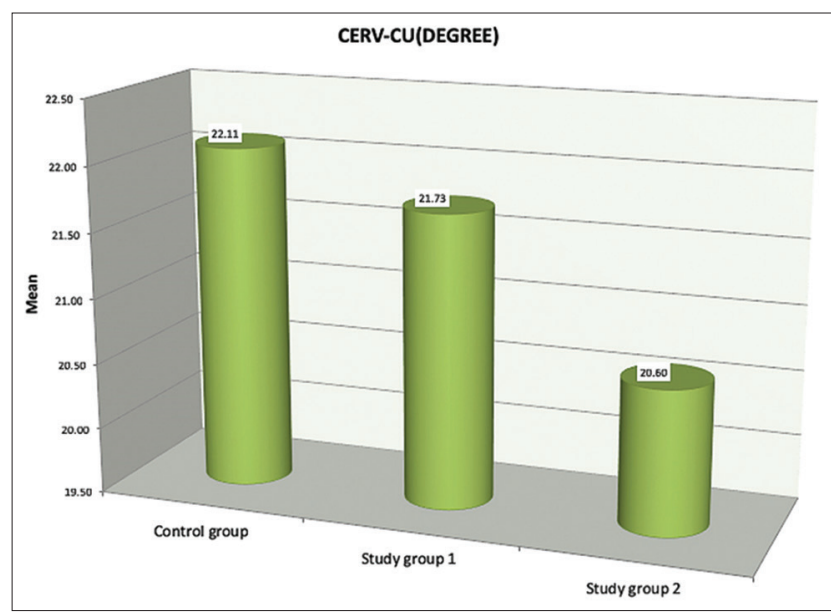

Graph 3: Graph represents decreased cervical curvature angel in the symptomatic study group with prolonged mobile phone usage. Cerv-CU(Degree): Angle formed between cervical spinous process; superior most point on external auditory meatus and outer canthus of eye

control and study groups in which there is a decrease in mean neck flexion angle in study Group 2, which is 
Table 2: Comparison of cephalometric measurements between the control group and Group 1 and Group 2

\begin{tabular}{|c|c|c|c|c|c|}
\hline Photographic measurements & Groups & $n$ & Mean \pm SD & ANOVA & $\boldsymbol{P}$ \\
\hline \multirow[t]{4}{*}{ CRN-CER (DEGREE) } & Control group & 20 & $16.05 \pm 4.05$ & 0.212 & 0.809 \\
\hline & Study Group 1 & 15 & $15.07 \pm 4.86$ & & \\
\hline & Study Group 2 & 15 & $15.93 \pm 5.23$ & & \\
\hline & Total & 50 & $15.72 \pm 4.59$ & & \\
\hline \multirow[t]{4}{*}{ CERV-CU (DEGREE) } & Control group & 20 & $22.11 \pm 5.32$ & 0.431 & 0.653 \\
\hline & Study Group 1 & 15 & $21.73 \pm 4.08$ & & \\
\hline & Study Group 2 & 15 & $20.60 \pm 4.87$ & & \\
\hline & Total & 50 & $21.54 \pm 4.79$ & & \\
\hline \multirow[t]{4}{*}{ CO-CI (MM) } & Control group & 20 & $3.48 \pm 4.58$ & 0.717 & 0.494 \\
\hline & Study Group 1 & 15 & $3.09 \pm 4.31$ & & \\
\hline & Study Group 2 & 15 & $1.81 \pm 3.33$ & & \\
\hline & Total & 50 & $2.86 \pm 4.14$ & & \\
\hline \multirow[t]{4}{*}{ C1-C2 (MM) } & Control group & 20 & $2.51 \pm 3.86$ & 1.003 & 0.374 \\
\hline & Study Group 1 & 15 & $2.47 \pm 3.90$ & & \\
\hline & Study Group 2 & 15 & $4.48 \pm 5.85$ & & \\
\hline & Total & 50 & $3.09 \pm 4.56$ & & \\
\hline
\end{tabular}

CRN-CER (DEGREE): Craniocervical angle; CERV-CU (DEGREE): Cervical curvature angle; C0-C1 (MM): Suboccipital space distance; C1-C2 (MM): Atlantoaxial distance. ANOVA: Analysis of variance

strongly suggestive of cervical lordosis. Graphs 4 and 5 revealed decreased suboccipital space distance and increased atlantoaxial distance in Group 2. These findings are consistent with a joint disability and decreased cervical muscular proprioception concerning compression in the intervertebral disc spaces in the cervical spinous process.

Among the subjects with TMD, the result was significantly associated with the criteria of mobile phone usage $(P<0.001)$. However, there was no positive correlation with TMD and the morphological changes assessed in the head and neck curvature on lateral profile photographs and lateral cephalograms.

\section{DISCUSSION}

Results in the present study are in accordance with studies by Saddu et al. ${ }^{[10]}$ In her research, the evaluation of head and craniocervical posture among patients with and without TMD proved significant difference $(P=0.045)$ with cervical curvature angle and positive results of cervical lordosis in patients with TMDs. Guan et al. conducted studies in which the detailed photographic measurements of the head and cervical posture when viewing mobile phone was assessed and values proved a significant increase in head tilt angle which was similar to the values observed in the present study. ${ }^{[11,12]}$

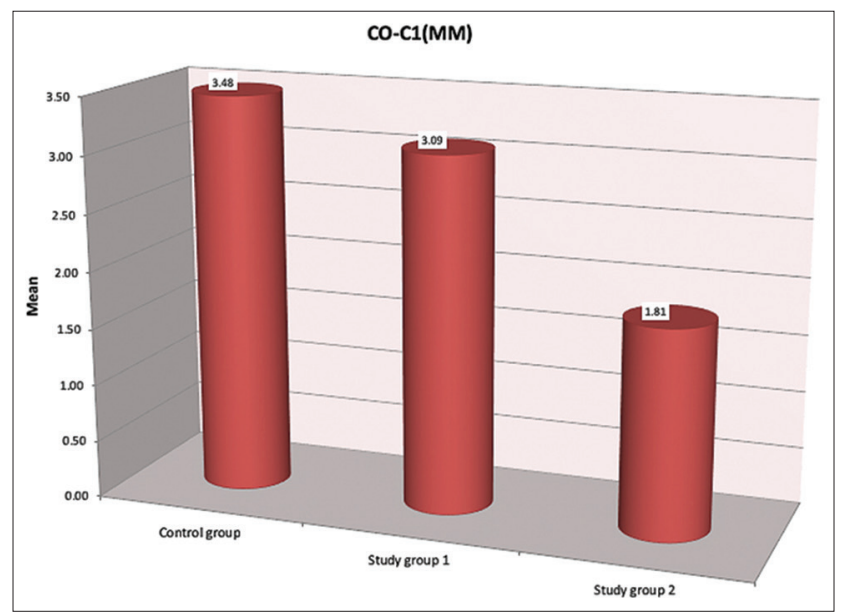

Graph 4: Suboccipital space is decreased in study Group 2 when compared to controls. C0-C1 MM - Suboccipital space distance; the perpendicular distance from the base of the occipital bone $(\mathrm{C} 0)$ to the posterosuperior point of the first cervical vertebra $(\mathrm{C} 1)$

The maintenance of space between $\mathrm{C} 0$ and C1 (suboccipital region) is essential, as it prevents compression of neurovascular elements. Any alteration in these spaces, such as revealed in the present study, exhibits evidence of articular hypomobility, muscular tension, and local pain. These changes are in line with the subjective signs and symptoms presented in individuals with functional disorders like TMD. 


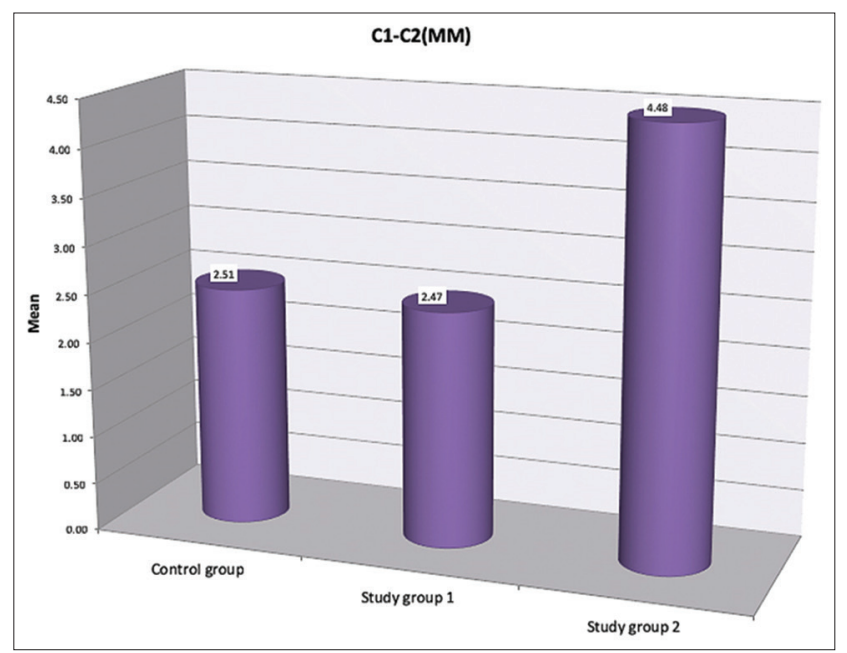

Graph 5: Increased atlantoaxial distance in the study Group 2 with comparison to controls and Group 2. C1-C2 MM - The perpendicular distance from the most inferior-posterior point of the posterior arch of the atlas (C1) to the most superoposterior point of the spinous process of axis (C2)

The following evidence of the adaptation of cervical flexors and extensor muscles is distinctively particular to our study findings only. Results from the present study in Graph 6 show a decrease in mean neck flexion angle for individuals in Group 1 compared to the control. This occurrence is due to the process of the muscular adaptation to compensate for the cervical hyperextension. As a result, the muscles tend to behave differently. These changes are hypothesized to establish during the initial stages of mobile phone usage. Later, the gradual increase in the neck flexion angle in Group 2, in comparison with Group 1, is strongly suggestive of postural variation. As the findings suggest, these changes can highlight the fact that a period of cervical musculature compensation exists following an increased duration and frequency of cervical hyperextension. Therefore, the muscles tend to behave differently. The resulting adaptation of cervical flexors and extensor muscles is notoriously particular to the present study findings only.

Halbert stated that there is a close anatomofunctional relationship between the masticatory system and the cervical region and the scapular centric, and the postural alterations of the head lead to a disadvantage to muscular biomechanics. ${ }^{[13]}$

Intentional craniocervical hyperextension in case of activities such as browsing and texting on the mobile phone induces altered head posture. ${ }^{[14]}$ The craniovertebral angle CVA and neck extensor muscle

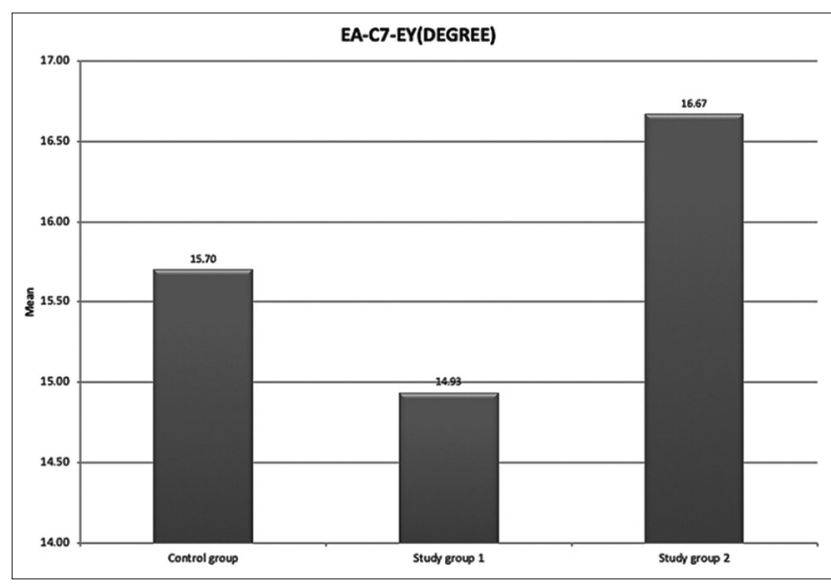

Graph 6: Increased head flexion angle in study Group 2. EAC7-EY (Degree) - Angle formed between EA (most superior point on external auditory meatus); C7 (Cervical spinous process); EY (landmark on outer canthus of eye)

strength is based on a length-tension relationship of the muscle presents in the anatomical plain of headand-neck region. Individuals with forwarding head posture show statistically lower CVA compared to individuals with normal head posture ${ }^{[15]}$ Excessive use of mobile phones for activities such as texting and browsing was observed in the symptomatic TMD group. These activities have led to decreased cervical curvature angle that cascaded to an exaggerated posterior rotation of the head that is known to cause many alterations such as reduced suboccipital space with signs of craniofacial pain. Hence, forward head posture was established due to tension in the cervical musculature ${ }^{[16]}$ Cervical hypolordotic malalignment, i.e., a tendency toward cervical kyphosis, is a remarkable finding in TMD's. ${ }^{[17]}$

However, there are numerous limitations to the study. First, other parameters for cervical lordosis were not considered. Second, the study population comprised a female predominance which does not allow generalization of the results to the entire study population. The various strengths of the study include finding a significant correlation between TMD's and the duration and frequency of mobile phone use. The use of photographs was a noninvasive, rapid method to assess craniocervical posture. Overall, the correlations indicate a causal relationship between craniomandibular position and TMD. They might either share common etiologic factors or somehow possess a phenomenal connection. 


\section{CONCLUSION}

Therefore, based on results in the present study, the relationship between the craniocervical disorder and TMD may be related strongly to a muscular-oriented component rather than an articular component. Cervical posture parameters such as decreased C7-VP and increased Ear-C7eye angulation were revealed to signify changes in forwarding head posture [Graph 6]. Although the alterations in variables that diagnose craniocervical dysfunction is not related to TMD due to the absence of significant P-value, the present study alone could not affirm that there is a relationship between craniocervical dysfunctions and temporomandibular disorders. Photogrammetry can serve as a noninvasive, rapid diagnostic tool in advancing the diagnostic era. Furthermore, it is interesting to note that TMD is not only related to the joint or muscular component but also to other signs and symptoms of activities related to daily lifestyle such as mobile phone usage.

\section{REFERENCES}

1. American Academy of Orofacial Pain. In: de Leeuw R, editors. Orofacial Pain: Guidelines for Assessment, Diagnosis and Management. $4^{\text {th }}$ ed. Chicago: Quintessence; 2008.

2. Fransson A, Chóliz M, Håkansson A. Addiction-like mobile phone behavior-validation and association with problem gambling. Front Psychol 2018;9:655.

3. Kee IK, Byun JS, Jung JK, Choi JK. The presence of altered craniocervical posture and mobility in smartphone-addicted teenagers with temporomandibular disorders. J Phys Ther Sci 2016;28:339-46.

4. López-de-Uralde-Villanueva I, Beltran-Alacreu $\mathrm{H}$, Paris-Alemany A, Angulo-Díaz-Parreño S, La Touche R. Relationships between craniocervical posture and painrelated disability in patients with cervico-craniofacial pain. J Pain Res 2015;8:449-58.

5. Toh SH, Coenen P, Howie EK, Straker LM. The associations of mobile touch screen device use with musculoskeletal symptoms and exposures: A systematic review. PLoS One 2017;12:e0181220.
6. Andrade AV, Gomes PF, Teixeira-Salmela LF. Cervical spine alignment and hyoid bone positioning with temporomandibular disorders. J Oral Rehabil 2007;34:767-72

7. Mannheimer JS, Rosenthal RM. Acute and chronic postural abnormalities as related to craniofacial pain and temporomandibular disorders. Dent Clin North Am 1991;35:185-208.

8. Schiffman E, Ohrbach R, Truelove E, Look J, Anderson G, Goulet JP, et al. Diagnostic criteria for temporomandibular disorders (DC/TMD) for clinical and research applications: Recommendations of the international RDC/TMD consortium network* and orofacial pain special interest group †. J Oral Facial Pain Headache 2014;28:6-27.

9. Lee WY, Okeson JP, Lindroth J. The relationship between forward head posture and temporomandibular disorders. J Orofac Pain 1995;9:161-7.

10. Saddu SC, Dyasanoor S, Valappila NJ, Ravi BV. The evaluation of head and craniocervical posture among patients with and without temporomandibular joint disorders-a comparative study. J Clin Diagn Res 2015;9:ZC55-8.

11. Guan X, Fan G, Wu X, Zeng Y, Su H, Gu G, et al. Photographic measurement of head and cervical posture when viewing mobile phone: A pilot study. Eur Spine J 2015;24:2892-8.

12. Guan X, Fan G, Chen Z, Zeng Y, Zhang H, Hu A, et al. Gender difference in mobile phone use and the impact of digital device exposure on neck posture. Ergonomics 2016;59:1453-61.

13. Halbert R. Electromyographic study of the head position. J Can Dent Assoc 1958;24:1-23.

14. Levangie PK, Norkin C. Joint Structure and Function: A Comprehensive Analysis. $4^{\text {th }}$ ed. Philadelphia, PA: F.A Davis; 2005.

15. Peolsson A, Marstein E, McNamara T, Nolan D, Sjaaberg E, Peolsson M, et al. Does posture of the cervical spine influence dorsal neck muscle activity when lifting? Man Ther 2014;19:32-6.

16. Rocabado M. Analisis biomecanico craneocervical a traves de una teleradiografia lateral. Rev Child Orthodod 1984;1:42-52.

17. Coskun Benlidayi I, Guzel R, Tatli U, Salimov F, Keceli O. The relationship between neck pain and cervical alignment in patients with temporomandibular disorders. Cranio 2018;1:1-6. 